\title{
Integrated Ethics Programs In The Healthcare Industry
}

Val Candy, WestCare Florida, USA

\begin{abstract}
The healthcare industry of the United States is undergoing extensive change to meet the needs of the Affordable Care Act of 2010. Organizations need to comply with a new macro-regulatory environment and establish institutionally based strategies that meet mandated standards and processes. The Act represents a shift from employer-sponsored insurance plans to a system where, depending upon subjective evaluations of what is on offer, consumers can shop around and purchase insurance plans listed in a federal or state marketplace. This means that healthcare providers are under intense political and public scrutiny. The new competitive environment may accelerate the shift from care-focused to efficiency-focused management initiatives within the healthcare industry and is viewed by some as an opportunity for contextual ambidexterity and conflict to emerge. In addition to establishing compliance programs to manage employees' ethical conduct in an effort to meet the narrow and deterministic demands of governmental pressure, organizations may also introduce ethical programs that reflect organizational commitment, individual integrity, and the willingness to admit mistakes and be creative in problem-solving exercises.
\end{abstract}

Keywords: Values-Based Ethics; Compliance-Based; Healthcare; Quality

\section{INTRODUCTION}

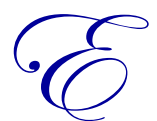

thics refers to the norms, principles, and standards of conduct governing individual and organizational behavior and decision-making (Trevino, Weaver, \& Reynolds, 2006; Spicer, Dunfree, \& Bailey, 2004).

Ethics is reflected in formal laws and regulations and also in informal institutions that promote codes of conduct or guidelines for making ethical decisions. Whereas some view ethics as the outcome of social pressure or a cosmetic attempt to appear more legitimate in the market place, others view ethics as a sincere effort to do the right thing regardless of social pressure (Quinn \& Jones, 1995). Still others adopt an instrumental approach claiming that ethics is a strategic tool for enhancing profit and sharing the benefits of conducting business through a stakeholder approach (Freeman, 1994; Svensson \& Wood, 2007).

This paper compares and contrasts integrity-based programs and compliance-based programs and the factors that contribute to, or moderate, ethical decision-making and behavior within organizations. Such factors include the macro-regulatory environment and institutionally based strategies that comply with mandated standards and processes. Arguments support contributions from the ethical climate theory (ECT) including organizational culture, individual status (power) and values, and motivational forces (both overt and latent) that influence organizational agents (leaders and followers) to break the rules (Simha \& Cullen, 2012; Weaver, Trevino, \& Cochran, 1999).

After examination of related theories and practices within the context of the healthcare industry, and based on the empirical and conceptual literature, an integrated ethics program should be promoted that reflects and reinforces institutional mandates at the systemic level and, further, an integrated approach should adopt specific characteristics or aspirations at the organizational level, as well as the professional norms and internalized values of employees, through a system of rewards and penalties for non-compliance at the individual level (Brown, Trevino, \& Harrison, 2005; Gehman, Trevino, \& Garud, 2013; Sandberg \& Tsoukas, 2011). 


\section{COMPLIANCE AND INTEGRITY-BASED PROGRAMS IN THE HEALTHCARE INDUSTRY}

The United States government is under intense political and public scrutiny during the nation's implementation of radical changes to the culture in which it delivers healthcare. The Affordable Care Act of 2010 represents a shift from employer-sponsored insurance plans to a system where, depending upon subjective evaluations of what is on offer, consumers can shop around and purchase insurance plans listed in a federal or state marketplace (Owen, 2009). The new competitive environment may accelerate the shift from care-focused to efficiency-focused management initiatives within the healthcare industry and is viewed by some as an opportunity for contextual ambidexterity and conflict to emerge (Bowerman, 2002; Suddaby et al., 2010). Federal and state agency regulatory initiatives emphasize the role of compliance in assuring the quality of care (DeMuro, 2010). This is discussed in relation to the use of competing goals in quality improvement teams in healthcare organizations and the ethical reporting of errors (Bowerman, 2002; MacPhail, 2012).

\section{Complementary Systems}

A compliance-based program is one that emphasizes rules of conduct and penalties for violation, whereas a values or integrity-based program is one that promotes a culture that reflects a set of core principles with the expectation that everyone will behave accordingly (Brown, Trevino, \& Harrison, 2005; Kish-Gephart et al., 2010; Pitesa \& Thau, 2013). Many claim the relationship between the two approaches, when managing and practicing ethics, is not mutually exclusive, dichotomous, or antagonistic in nature (Weaver \& Trevino, 1999). Research suggests that benevolent and principled organizational environments or climates are positively associated with ethical intentions and ethical behaviors (Trevino, 1993; Victor \& Cullen, 1988). Studies also claim how integrating compliance into operational core processes (training and discipline) can enhance perceptions of internal and external legitimacy (MacLean \& Benham, 2013).

\section{Ethical Climate Theory (ECT)}

Ethical climate theory (ECT) has tested and offered explanations for how shared perceptions, formal and informal procedures, policies, and practices can be captured into an integrity-based program using characteristics of compliance to control organizational behavior (Simha \& Cullen, 2011). Here, an ethical climate may be defined as the shared perception, or collective evaluation, of what is right behavior within a given context and how it influences work-place decision-making and behavior (Arnaud, 2010; Bulutar \& Oz, 2009; Wang \& Hsieh, 2012).

MacLean and Benham (2013) argue that compliance-based ethics programs can erode organizational citizenship behaviors and commitment by using external legitimacy as a facade for enduring integrity. While this may have repercussions for the ultimate care and consistency of patient or consumer satisfaction, any incongruence between the imagined and actual ethical climates in the immediate workplace may contribute to increased turnover (Holtom, Mitchell, Lee, \& Inderrien, 2005). Where this occurs, a medical professional may engage in rule-breaking behavior, justified through either a utilitarian approach or the categorical imperative (Moore et al., 2006). On the other hand, a disappointed or resentful professional may conclude that a change of employer will be more likely to meet the anticipated cognitive, affective, and tangible rewards, such as financial expectations (Holtom et al., 2005). Although a full discussion is beyond the scope of this paper, the loss of knowledge capital and the direct costs of such dysfunctional turnover are well documented in the literature (Holtom et al., 2005).

\section{Conceptualizing an Honor Code}

There has been a broad range of empirical research studying theories and practices of ethical programs and their characteristics at the individual, local, and cosmopolitan levels of analyses (Simha \& Cullen, 2012). A report from the Office of Economic Development (Murphy, 2011) claimed that the majority of developed nations sought to manage ethical behavior in public sector entities through a variety of systems, processes and programs. The report reflected what the scholarly literature refers to as a typology of compliance-based versus integrity-based management (Brown, Trevino, \& Harrison, 2005; Trevino, 1993). 
At the organizational level, Gehman et al. (2013) conducted a longitudinal and mixed-methods study to explore how students of an elite business school (Beta Business School) and public research university apply values in the conceptualization or emergence of an honors code system. The school's website had formally introduced an honor code reflecting values such as honesty, integrity, and accountability. Beta members were required to sign a pledge to uphold those values, to accept agreed sanctions admonished by a student judiciary panel, to take exams without proctors, and to report any wrongdoing or cheating on the part of their peers (Gehman et al., 2013).

Although the convenience sample and ethnographic approach limits the study's external validity or generalization, the credibility of its findings is worthy of further investigation within the healthcare industry (Gehman et al., 2013). These authors claim that the complex and high-pressurized environment of Beta School shares similar characteristics to those in which medical professionals and institutions face ethical dilemmas and practice problem-solving on a virtual daily basis (Gehman et al., 2013). In particular, the pledge outlined aspirations and values of the highest standards that graduates should follow when they enter their respective career paths. However, even while still part of the Beta School, ethnographic observations (where two of the researchers served as observer-participants) recorded how conflict emerged when students witnessed acts of wrongdoing and dishonesty on the part of their peers.

Gehman et al. (2013) observed how value tensions emerged when certain Beta members were asked to comment on possible sanctions for other Beta members who had violated the honor code of conduct at one time or another during the course of the study. For instance, despite having supported sanctions against students who had actually cheated at other business schools, Beta members argued that reporting their peers' dishonest acts would violate the perceived greater values associated with collaborative teamwork (Gehman et al., 2013). This implies that leadership commitment to the use of compliance-based programs, with or without external auditors, may be required to enforce aspirational goals such as those highlighted in Beta Business School's pledge. Further, such a position may be required to meet, or exceed, internal and external stakeholders' reasonable expectations from a healthcare organization that deals with matters of life and death on a daily basis, and with relatively high reported error rates. In other words, an integrity or values-based program needs to be complemented with a compliance-based program that highlights and enforces penalties for clearly defined acts of deviance (Brown, Trevino, \& Harrison, 2005).

\section{Leadership}

Researchers suggest that leadership and senior executives play a critical role in shaping an organization's culture and whether it adopts a compliance-based or aspirational-based view of conducting business (Brown \& Trevino, 2009; Fanelli \& Misangyi, 2006). In this context, an aspirational-based program is used interchangeably with definitions of values-based and integrity-based programs. Charismatic leadership has been associated with sharing and disseminating aspirations as culturally expected norms (Sims, 2000). However, the literature has also reported how unethical behavior can emerge when a leader is perceived as communicating aspirations, assumptions, and interrelated beliefs for personal gain rather than organizational benefits (Maner \& Mead, 2000). Winter, Styliano, and Giacolone (2004) found that individuals responded differently to unethical informational technology practices depending upon whether leadership is perceived as operating under ethically ideological principles or as rewarding Machiavellian behaviors and attitudes.

\section{Sub-Cultures}

Research suggests that sub-cultures can fragment an organization's culture and are resistant to values imposed by senior executives and top leadership in environments where virtual forms of organizing work through technology have become commonplace (Cha \& Edmondson, 2006). This may have consequences for managing and credentialing large networks of medical providers, hospitals, and community health centers where the scope for ambiguity in the interpretation of published rules and guidelines leads to permitted and contested forms of rulebreaking (Martin, Lopez, Roscigno, \& Hodson, 2013). Further, following electronic verification of individual provider and institutional certifications and licenses, scheduling in-person monitoring visits by government and health insurance auditors, tasked with ensuring full compliance with federal and state regulations, may cause resentment. 
Martin et al. (2013) found that the administration of one nursing home, that had enforced tighter rules to deter theft among the care staff, was subjected to an excessive amount of monitoring visits to ensure that staff operated in compliance with the new internal rules and regulations. Whereas some organizations turn a blind eye to individual deviance, or rule breaking, Dodson (2009) found that some front-line managers of low-wage workers (including nursing assistants and mental health support staff) uphold what they claim are basic principles of decency and justice. Hence, such managers ignore minor deviance (including theft) since they consider the organization to be acting immorally by not paying a living wage (Dodson, 2009).

\section{Aspirations}

According to Martin (2005), cultures are inherently homogenous, so socially constructed realities are formed through the processes of sense-making and enactment. As a consequence, these may generate either complementary or competing interpretations of aspirations and values, as well as perceived responsibilities (Martin, 2005). Much discussion of organizational leadership is restricted to influences that are viewed from within a closedsystem perspective and that outline responsibilities and accountabilities (Martin, 2005). These studies also reveal how large mechanistic organizations often engage in decoupling - an approach that satisfies external stakeholders while institutionalizing rule breaking (Martin, 2005).

Gehman et al. (2013) argued that the existing literature fails to offer adequate conceptual explanations, or theoretical evidence supported by empirical findings, of the dynamic nature of values-based practices; that is, the process of infusing an organization with values that define what is right or wrong and good or bad, as a means in and of themselves, and that are transferred from open systems that take into account the impact of external partners, social movements, and other stakeholders who either share, influence, or seek to change an organizational culture (Gehman et al., 2013). As with other strategic business outcomes, ethics is inextricably linked to an organization's purpose and its responsibilities for gathering and redistributing wealth, or the differential benefits of being in business, beyond the egoism versus altruism perspectives.

\section{Ethical Framework: Utility versus Justice}

According to the teleological school of thought, egoism involves the maximization of self-interest. Within this framework, ethical dilemmas are evaluated based on the consequences of actions rather than the actions per se (Balotsky, 2009). Proponents of this approach declare ethical activity as the one that causes the greatest amount of good to the greatest number of people - or causes the least amount of harm to stakeholders overall. However, that does not imply that the benefits or losses associated with an ethical line of action are equally distributed among all stakeholders as evidenced in the relationship between pharmaceutical companies, Medicare, tax-payers, patients, and their prescribing physicians (Balotsky, 2009).

The deontological school of thought is based on Kant's categorical imperative and claims that all actions are either right or wrong and should be treated accordingly (Balotsky, 2009). Within this ethical framework, benefits and losses are shared equally through distributive justice. This is achieved in several forms through societal norms, including retribution, punishment, and compensation, whereby a loss incurred should be matched with a repayment of equal value (Balotsky, 2009). The second major principle of the categorical imperative is virtue ethics that encompasses values, aspirations, or the socially and culturally engineered rules of conduct that define ethical behavior within a given society or environment.

Borrowing principles from the utilitarian perspective, Balotsky (2009) recommended that society would be better served if pharmaceutical companies cap the price of prescribed medications for Medicare enrollees and, further, that Medicare allows hospitals to increase access for the elderly. These proposals would maintain profit margins for research and product development on the part of pharmaceutical companies that could also share the risks of introducing new technology with hospitals. In addition, it would provide an innovative, yet affordable, prescription drug program for the ever-increasing elderly population that has been a key contributor to proposals of radical change in culture and procedure within the healthcare system (Balotsky, 2009). 


\section{Stockholder and Stakeholder Approaches}

According to the stockholder approach (Friedman, 1970), corporate leadership is misguided in claiming personal aspirations and social responsibility as a core goal. Rather, corporations and their executives should act as agents for the good of the stockholders who, in effect, own the corporation. From the stockholder perspective, an executive or agent of the corporation, who spends stockholders' investments on matters that are morally seductive on a personal level or that are the business of government, is reckless at best and unethical at worst. The executive's purpose is to maximize profits and reduce risk rather than spend money on acts to benefit a society, unless those acts emerge as a by-product of conducting business for stockholders' gain (Friedman, 1970).

On the other hand, the stakeholder approach (Freeman, 1994) claims that an organization's responsibilities extend beyond the profit motive to one in which the job of the manager or executive is to manage relationships among all interested parties. From this perspective, a healthcare organization should endeavor to satisfy a broad range of interrelated groups, including patients, employees, suppliers, and the community at large. Stieb (2009) reframed Freeman's re-conceptualization of managerial capitalism by introducing the Kantian concept of distributive justice that lends support for an ethics program based on a control system that extends beyond the word or the law or regulation to include integrity or values-based decision-making.

\section{Power}

The power differential between physician and non-physicians in Academic Medical Centers (AMCs) may undermine attempts to improve processes and programs when deficiencies have been identified and when underlying personal and professional values clash (Seshadri, Piderit, \& Giridharadas, 2012). This is all the more important since AMCs are active in formulating and driving policy and practice throughout approximately 5,500 hospitals scattered across the United States. The degree of trade-off (or ambidexerity) between apparently competing goals needs to be accommodated through an integrated approach to ethics based on compliance and values and the collective agreement that personal views may need to be set aside for the greater good (Seshadri et al., 2012). In such cases, utility seems to be the underpinning ethical philosophy when evaluating the risks, or tradeoff, of competing values or goals in quality improvement teams.

\section{Government Regulation: Healthcare Industry Acts}

The Organization for Economic Cooperation and Development (Murphy, 2011) reported that the United States' (U.S.) social and political processes are exemplar of a compliance-based national culture. This means that governments and corporations emphasize conformance with complex legislation, strict adherence to bureaucratic rules and regulations, and penalties for wrongdoing on the part of organizations and the individuals who manage them (Trevino et al., 2006). The U.S. government has passed numerous laws and regulations as a result of wellpublicized organizational misconduct, corporate scandals, and concerns about the privacy of patient records. Indeed, The Sarbanes-Oxley Act and the United States Sentencing Commission Guidelines (USSC, 1994) are considered as mandates for organizations to develop and promulgate compliance programs that emphasize penalties for non-compliance (Dalton \& Metzger, 1994; Trevino \& Weaver, 2003).

Acts specific to the healthcare industry include the Health and Insurance Portability and Privacy Act (HIPPA) and the implementation of electronic health record systems (EHR) by 2014, as mandated through the Affordable Care Act (2010). The fact that so many organizations have created compliance programs in enforcing these acts, in general, is testimony to the extent to which compliance programs are considered to help in securing external legitimacy within a given industry or market (Weaver, Trevino, \& Cochran, 1999b). However, Roberts (2012) argues that while conformity to legislation is a necessary way to avoid costly litigation, it also risks suppressing so-called higher ethical standards by removing the incentives to develop more complex integrity-based programs. Indeed, this mirrors arguments that a regulated minimum wage may set the average wage at an artificially low level and that negative consequences affect unskilled, often front line, workers at a disproportionate rate. 


\section{Compliance-Based Programs}

Compliance-based programs are established to prevent unlawful conduct by ensuring that employees conform to externally imposed rules. However, many organizations use formal compliance programs as a cosmetic distraction from a business as usual culture without penalty or concern for wrongdoing (Moore, Tetlock, Tanlu, \& Bazerman, 2006; Weaver et al., 1999b; Westphal, Gulati, \& Shortell, 1997). Research suggests that, at the systemic level, external auditors are prone to awarding certifications, licenses, and granting legitimacy through quality improvement programs, or accreditation renewals, in recognition of written compliance programs that do not always transfer to overt and consistent practices (MacLean \& Benham, 2013).

External auditors, or expert consultants, may face conflicts of interest in much the same way physicians, who are responsible for acting in the best interest of their patients, may compromise that task when making referrals to clinics and pharmacies in which they own a controlling interest (Moore et al., 2006). It is widely documented that American healthcare is arguably the most effective system in terms of patient treatment outcomes and prescribed medications (Balotsky, 2009). The Medicare legislation was signed into legislation in 1965 to finance healthcare costs of the elderly and the poor, although neither market-based approaches nor government regulation has since controlled the rising cost of providing care and prescription drugs (Nichols et al., 2004).

\section{Financial Conflicts of Interest in Medicare: Egoism versus Altruism}

Today, Medicare pays physicians more for prescribing expensive cancer treatment medications than for prescribing generic or less expensive, but arguably equally efficient, treatments (Emanuel, 2012; Hampson et al., 2007). The issue is all the more contentious when the relative return on investment for the patient is added to the equation. For example, research argues that these specific drugs cost the equivalent of $\$ 100,000$ for every four weeks of life (regardless of quality of life criteria) purchased during the final few months, or even weeks, of a patient's life (Hampson et al., 2007).

The author neither implies that physicians are consciously seeking to make a profit at the expense of an individual receiving palliative care nor seeks to blur the boundary between the insurance industry and the healthcare industry and the risks and benefits of macro-economic policy governing the Affordable Care Act. Instead, the intention is to question how a physician's judgment may be affected by this financial conflict of interest during a time when the patient's ability to be objective and rational is reduced through emotional vulnerability (Moore et al., 2006). Such issues may be framed within the objectivism framework that debates the role of social pressure and rational thinking in decision-making (Barry \& Stephens, 1998).

From a philosophical perspective of objectivism, altruism is considered to be an immoral act while egoism is the moral, yet humble, path (Locke \& Becker, 1998). This controversial statement supports Rand's proposition that morality dictates that individuals should take the high road to rational self-interest (egoism) rather than the altruistic path layered with self-sacrificial acts that place life second to others' interests (Locke \& Becker, 1998). According to Becker (1998), integrity in organizations is a process through which all individuals should place their own self-interests first and is ethical only when an action is performed within the agreed scope of individual power and does not initiate force against others.

While Barry and Stephens (1998) argued that Becker's views are inherently flawed, as well as academically reckless in crossing multi-disciplinary boundaries, these researchers failed to support their case proclaiming that objectivism overlooks the role of power and oppression. Indeed, Locke and Becker (1998) responded to their critics by concluding that integrity is the equivalent of loyalty "in action to rational principles and values" (p. 174). However, the question that needs to be asked is how such rational values are agreed and expressed, or translated into standards of behavior, at an organizational or collective level, regardless of individual cognitive or emotional dissonance or external pressure to conform.

\section{Social Context and Internal Regulation}

Research suggests that employees face moral issues on a daily basis and that ethical decision-making is a reflection of social influences (Martin et al., 2013). In addition to establishing compliance programs to manage 
employees' ethical conduct in an effort to meet the narrow and deterministic demands of governmental pressure, organizations may also introduce ethical programs that reflect organizational commitment, individual integrity, and the willingness to admit mistakes and be creative in problem-solving exercises (Weaver \& Trevino, 1999). This is particularly relevant in today's competitive environment since research suggests that organizational commitment is an antecedent to organizational effectiveness (Gehman, Trevino, \& Garud, 2013). These internal rules communicate compulsory, or discretionary, behavior that define company values and become part of the formalized control system to a lesser or greater extent (Trevino, 1993).

Formalized internal control systems include written codes of ethics that outline expectations and guide decision-making, ethics committees that develop ethical policy and evaluate individual and organizational level behaviors, ethics communication systems for reporting violations (anonymously and confidentially), training programs, and ethical officers (Weaver et al., 1999). This paper argues that government-sponsored training and accreditation programs bridge the gap between external and internal regulatory systems of control that only partially mirror an integrated compliance and values-based program of ethics (Gehman, Trevino, \& Garud, 2013; Polidoro, 2013).

\section{Decoupling and Error Reporting: Certification and Licensure Programs}

The Department of Children and Families (DCF) is a government-agency that offers state-funded substance abuse and mental health service providers (for profit and not-for-profit entities) the opportunity to operate programs under licensure, provided certain criteria have been met. The list of criteria includes, but is not exhaustive to, the annual completion of mandatory staff training requirements, health and safety standards, maintenance of financial systems, credentialing systems, accessibility and diversity standards. However, from this perspective, systems and processes developed to satisfy these non-negotiable standards remain coercive since funding is entirely dependent upon successful annual licensure renewal (Gehman et al., 2013).

Despite rhetoric and storytelling that boasts of organizational cultures that have institutionalized quality standards of care, the link between - for example, the reaccreditation of an organization by the recognized gold star industry standard and collective aspirational values or integrity - remains ambiguous (Martin et al., 2013). Decoupling is the phenomenon observed when an organization complies with explicitly stated formal rules to satisfy external auditors, while maintaining the status quo to satisfy internal needs (Martin et al., 2013). In a study of quality improvement where team members represented various organizational departments and functions, MacPhail (2012) used logistical regression as a means of examining the link between compliance-based and integrity-based ethics within the context of reporting errors at a leading teaching hospital. The findings of this study found that while errors have been shown to facilitate improved performance through organizational adaptive learning, using them as tools for organizational - or adaptive - learning was rare (MacPhail, 2012).

At the individual level, participants reported that they perceived errors as stressful and threatening. Further, individuals who admitted to making errors avoided learning opportunities in an effort to conceal perceived personal uncertainty or weakness (MacPhail, 2012). This author concluded that although the majority of errors does not lead to organizational disasters or crises, it may erode an integrity-based culture while reinforcing a threatrigidity effect that implements past habits, as opposed to flexible thinking, during problem-solving. The implications for true quality improvement in complex high-risk organizations, such as within the healthcare sector where widely publicized reports estimate as many as 98,000 deaths per year through error, is bleak considering the prevalence of compliance-based programs that meet external regulatory standards (Classen et al., 2011).

\section{Integrity-Based Programs}

The use of regulatory standards in the form of awards, or certifications, enables an organization to imply, or signal, attributes that are not directly observable. These are deemed to capture an organizational culture and character that reduces uncertainty in the market and among stakeholders (Polidoro, 2013). This paper supports the view that integrity-based programs, based on values, honesty, openness, and commitment, are common in public sector organizations that are found to be more willing than private sector organizations to deliver bad news when wrongdoing, or error, is discovered. 


\section{Transparency}

The medical professional-patient relationship is based upon honesty and mutual respect and medical schools socialize professionals with fundamental principles of care that place patient needs first (Holtom et al., 2005). Questions about the transparency of information provided to patients when making decisions about care, and whether it should include the cost of care options and source of funding at the point of service, risk undermining the relationship (Thatcher \& Clemons, 2008; Turilli \& Floridi, 2009). This is a critical concern for most healthcare organizations that are shifting emphasis to managing care using business efficiency models under the Affordable Care Act.

Research in the United Kingdom and the United States suggests that registered nurses, or nurse managers, are the best placed and most trusted source of information for employees and patients experiencing changes in the healthcare system (Holtom et al., 2005; Platt \& Staniszewska, 2011). However, a nurse or physician tasked with using cost control tactics to reduce the average length of hospital stays for the benefit of the employing organization may feel personal or professional conflict when making decisions about whether or not to discharge a patient based on the profit motive. Indeed, under such circumstances, an individual may choose to comply with the written code of conduct or be tempted to violate a specific rule, deemed to be relatively harmless, where minor deviance satisfies a perceived greater need for self or for others (Martin, Lopez, Roscigno, \& Hodson, 2013).

\section{CONCLUSION}

The author discussed the key differences between compliance-based and integrity-based ethics programs and demonstrated how they apply to the healthcare industry through certification and licensure requirements, as well as through internal quality improvement teams. A compliance-based program is one that emphasizes rules of conduct and penalties for violation, and, while its utility is indisputable, healthcare organizations may prefer an integrated approach to managing ethics that includes collective understanding of organizational aspirations, values and standards (Kish-Gephart et al., 2010; Pitesa \& Thau, 2013).

Adopting an integrated approach may help reduce the negative effects of decoupling and ensure that healthcare organizations, individual providers, and clinicians align internal standards so they exceed the regulatory standards through which an organization can gain legitimization in the marketplace (MaClean \& Benham, 2013). However, the author does not support excessive rules or regulations but does support the need for healthcare organizations and medical professionals to adopt greater transparency in dealing with reported errors over and above external requirements (McPhail, 2013; Polidoro, 2013). The role of leadership was discussed in role-modeling desired behaviors that reflect aspired values and also in communicating organizational policies, procedures, and penalties for dealing with non-compliance.

\section{AUTHOR INFORMATION}

Val Candy is a $\mathrm{PhD}$ candidate in management and organization. She has published in the areas of organizational behavior, leadership, and strategy. Val consults on a range of government reform issues including healthcare management and waste diversion. She has worked extensively in leadership positions in the United Kingdom, as a policy development advisor for the Department of Education and Skills, and in the United States where she is developing a credentialing and accreditation process for a national not-for profit. E-mail: vucandyms@gmail.com

\section{REFERENCES}

1. Arnaud, A. (2010). Conceptualizing and measuring ethical work climate: Development and validation of the Ethical Climate Index. Business and Society, 49(2), 345-358.

2. Balotsky, E. R. (2008). Where strategy and ethics converge: Pharmaceutical industry pricing policy for Medicare Part D beneficiaries. Journal of Business Ethics, 84(1), 75-88.

3. Barry, B., \& Stephens, C. U. (1998). Objections to an objectivist approach to integrity. Academy of Management Review, 23(1), 162-169. 
4. Becker, T. E. (1998). Integrity in organizations: Beyond honesty and conscientiousness. Academy of Management Review, 23(1), 154-161.

5. Bowerman, M. (2002). Isomorphism without legitimacy? The case of the business excellence model in local government. Public Money \& Management, 22(2), 47-52.

6. Brown, M. E., Trevino, K. L., \& Harrison, D. A. (2005). Ethical leadership: A social learning perspective for construct development and testing. Organizational Behavior and Human Decision Processes, 97(1), 117-134.

7. Bulutar, F., \& Oz, E. U. (2009). The effects of ethical climates on bullying behavior in the workplace. Journal of Business Ethics, 26(2), 147-167.

8. Cha, S. E., \& Edmondson, A. C. (2006). When values backfire: Leadership, attribution, and disenchantment in a values-driven organization. Leadership Quarterly, 17, 57-78.

9. Dalton, D. R., \& Metzger, M. B. (1994). The "new" U.S. Sentencing Commission guidelines: A wake-up call for corporate America. Academy of Management Executive, 8(1), 7-14.

10. DeMuro, P. R. (2010, February). Accountable care organizations and evolving integrated delivery systems - the new frontier in compliance challenges. Journal of Health Care Compliance, 21-24.

11. Dodson, L. (2009). The moral underground. New York: New Press.

12. Emanuel, E., Tanden, N., \& Altman, S. (2012). A systematic approach to containing health care spending. New England Journal of Medicine, 367, 949-954.

13. Fanelli, A., \& Misangyi, V. F. (2006). Bringing out charisma: CEO charisma and external stakeholders. Academy of Management Review, 31(1), 1049-1061.

14. Freeman, R. E. (1994). The politics of stakeholder theory. Business Ethics Quarterly, 4(4), 409-420.

15. Friedman, M. (1970, September 13). The social responsibility of business is to increase its profits. New York Times, pp. 32, 122-124.

16. Gehman, J., Trevino, L. K., \& Garud, R. (2013). Values work: A process study of the emergence and performance of organizational values practices. Academy of Management Journal, 56(1), 84-112.

17. Hampson, L., Joffe, S., Fowler, R., Verter, J., \& Emanuel, E. (2007). The frequency, type, and monetary value of financial conflicts of interest in cancer clinical research. Journal of Clinical Oncology, 25(24), 3609-3614.

18. Holtom, C., Mitchell, T., Lee, T., \& Inderrieden, E. (2005). Shocks as causes of turnover: What they are and how organizations can manage them. Human Resource Management, 44(3), 337-352.

19. Kish-Gephart, J. J., Harrison, D. A., \& Trevino, L. K. (2010). Bad apples, bad cases, and bad barrels: Metaanalytic evidence about sources of unethical decisions at work. Journal of Applied Psychology, 95(1), 1-31.

20. Locke, E. A., \& Becker, T. E. (1998). Rebuttal to a subjectivist critique of an objectivist approach to integrity in organizations. Academy of Management Review, 23(1), 170-175.

21. MacLean, T., \& Benham, M. (2013). The dangers of decoupling: The relationship between compliance programs, legitimacy, perceptions, and institutionalized misconduct. Academy of Management Journal, 53(6), 1499-1520.

22. Maner, J. K., \& Mead, N. L. (2010). The essential tension between leadership and power: When leaders sacrifice group goals for the sake of self-interest. Journal of Personality and Social Psychology, 99(3), 482497.

23. Martin, A. W., Lopez, S. H., Roscigno, V. J., \& Hodson, R. (2013). Against the rules: Synthesizing types and processes of bureaucratic rule-breaking. Academy of Management Review, 38(4), 550-574.

24. McPhail, L. (2011, January). Organizational review of adverse events at an academic medical center. Academy of Management Proceedings, 1-6. doi:10.5465/AMBPP.2011.65870512

25. Moore, D. A., Tetlock, P. E., Tanlu, L., \& Bazerman, M. H. (2006). Conflicts of interest and the case of auditor independence: Moral seduction and strategic issue cycling. Academy of Management Review, 31(1), 10-29.

26. Murphy, J. (2011, October). Society of corporate compliance and ethics. Retrieved from http://www.oecd.org/regreform/sectors/48849071.pdf

27. Owen, C. L. (2009). Consumer-driven healthcare: Answer to global competition or threat to social justice? Social Work, 54(4), 307-315.

28. Pitesa, M., \& Thau, S. (2013). Compliant sinners, obstinate saints: How power and self-focus determine the effectiveness of social influences in ethical decision making. Academy of Management Journal, 56(3), 635658. 
29. Polidoro, F. (2013). The competitive implications of certifications: The effects of scientific and regulatory certifications on entries into technical fields. Academy of Management Journal, 56(2), 597-627.

30. Quinn, D., \& Jones, T. (1995). An agent morality view of business policy. Academy of Management Review, 20(1), 22-42.

31. Sandberg, J., \& Tsoukas, H. (2011). Grasping the logic of practice: Theorizing through practical rationality. Academy of Management Review, 36(1), 338-360.

32. Seshadri, S., Piderit, S. K., \& Giridharadas, R. (2012). How many minds does a team have? Contextual ambidexterity and goal harmony in healthcare. Academy of Management Proceedings. doi: 10.2307/256873

33. Simha, A. M., \& Cullen, J. B. (2012, November). Ethical climates and their effects on organizational outcomes: Implications from the past and prophecies for the future. Academy of Management Perspectives, 20-34.

34. Sims, R. A. (2000). Changing an organization's culture under new leadership. Journal of Business Ethics, 25, 66-78.

35. Simsek, Z. (2009). Organizational ambidexterity: Towards a multilevel understanding. Journal of Management Studies, 46(4), 597-624.

36. Spicer, A., Dunfree, T., \& Bailery, W. (2004). Does national context matter in ethical decision-making? Academy of Management Journal, 47(1), 610-620.

37. Stieb, J. A. (2009). Assessing Freeman's stakeholder theory. Journal of Business Ethics, 87, 401-414.

38. Suddaby, R., Elsbach, K. D., Greenwood, R., Meyer, J. W., \& Zilbert, T. B. (2010). Organizations and their institutional environments: Bringing meaning, values, and culture back in. Academy of Management Journal, 53(1), 1234-1240.

39. Svensson, G., \& Wood, G. (2007). A model of business ethics. Journal of Business Ethics, 77, 303-322.

40. Thatcher, M. E., \& Clemons, E. K. (2008). Bundling economics under adverse selection in the individual health insurance market. Journal of Information Technology and Application, 9(2), 1-25.

41. Trevino, L. K. (1993). The social effects of punishment: A justice perspective. Academy of Management Review, 17(1), 647-676.

42. Trevino, L. K., Weaver, G., \& Reynolds, S. (2006). Behavioral ethics in organizations. Journal of Management, 33(1), 951-990.

43. Turilli, M., \& Floridi, L. (2009). The ethics of transparency. Ethics in Informational Technology, 11(1), 105-112.

44. Victor, B., \& Cullen, J. B. (1988). The organizational bases of ethical work climates. Administrative Science Quarterly, 33(1), 101-125.

45. Wang, Y. D., \& Hsieh, H. H. (2012). Toward a better understanding of the link between ethical climate and job satisfaction: A multi-level analysis. Journal of Business Ethics, 105(1), 535-545.

46. Weaver, G. R., \& Trevino, L. K. (1999). Compliance and values-oriented ethics programs: Influences on employees' attitudes and behaviors. Business Ethics Quarterly, 9(1), 315-335.

47. Weaver, G. R., Trevino, L. K., \& Cochran, P. L. (1999a). Corporate ethics programs as control systems: Influences of executive commitment and environmental factors. Academy of Management Journal, 42(1), 41-57.

48. Weaver, G. R., Trevino, L. K., \& Cochran, P. L. (1999b). Integrated and decoupled corporate social performance: Management commitments, external pressures, and corporate ethics. Academy of Management Journal, 42(1), 539-552.

49. Westphal, J. D., Gulati, R., \& Shortell, S. M. (1997). Customization and conformity? An institutional and network perspective on the content and consequences of TQM adoption. Administrative Science Quarterly, 42(1), 366-394.

50. Winter, S. J., Stylianou, A. C., \& Giacalone, R. A. (2004). Individual differences in the acceptability of unethical information technology practices: The case of Machiavellianism and ethical ideology. Journal of Business Ethics, 54(1), 279-301. 